
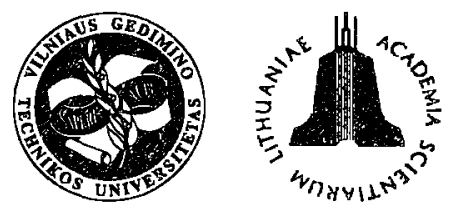

ISSN 1648-4142 TRANSPORT

http:/www.vtu.lt/english/editions

TRANSPORT - 2002, Vol XVII, No 2, 39-45

\title{
THE ROLE OF A TIRE IN VEHICLE AND ROAD INTERACTION
}

\author{
Arūnas Rutka ${ }^{1}$, Jonas Sapragonas ${ }^{2}$ \\ Kaunas University of Technology, Kęstucio g. 27, LT-3004 Kaunas, Lithuania.
}

Received 200201 10; accepted 20020304

\begin{abstract}
Major difficulties in road surface description lies in the evaluation of the tire and road interaction. Main purpose of this paper is to analyse the influence of the tire in vehicle and road interaction with the purpose to choose more commons, but enough precise tire models. Data of profile used in investigations were measured in real roads. For the investigation of the tire's smoothing function two models were used: flexible narrow ring $-2 \mathrm{D}$ estimates the tire and road contact in a line and flexible band - 3D estimates dimensional contact between the road and tire. Results of computations are presented in figures. There were determinate that tire does not fully smooth irregularity of surface texture level.
\end{abstract}

Keywords: dynamics, car model, tire, road

\section{Introduction}

We are facing the problem of the road surface description in vehicle movement on the known road tract, even if a road profile is known $[1,2]$. Major difficulties in this description lie in the evaluation of tire and road interaction. In this paper this interaction is investigated in two aspects:

1. The rolling wheel does not reflect the irregularities of the road, but the tire has a smoothing ability and this must be evaluated in the description of a very uneven road [3-5].

2. It evaluates the changes in the length of a tire and road contact during the deformation of the tire, if a wheel rolls on the road irregularities.

Theoretically, even if the deformation is linear, the tire must be described as a nonlinear element because the contact area with a road surface is constantly changing. The dependence between contact dimensions (contact length) and vertical deformation, if the tire is deformed, is distinctly not linear.

Lately the authors who investigate the interaction of tire and road, when they solve noise problems [6-8], they pay attention to the fact that the tire not always can smooth even the texture level irregularities of the road surface.

The main purpose of this paper is to analyse the influence of a tire in the vehicle and road interaction in order to choose more common, but enough precise tire models. The investigation of the estimation of tire and road contact is limited by linear and flat models, but the structure of a tire (kvazistatic model) was not evaluated.

\footnotetext{
${ }^{1}$ E-mail: arunasrut@takas.lt

2E-mail: josapr@mf.kru.lt
}

\section{The Description of a Road}

The data of the typical Lithuanian road tracts are taken from the experiments $[9,10]$ and were measured in different real roads. The data of every road profile have specific indication that are characteristic only to this tract; in this case the possibilities of formalization of particular road profile data were analyzed. In data formalization it was evaluated that the main part of road profile records was made with a laser profilograph DYNATEST 5051 RSP which software estimates the road roughness in IRI (Intemational Roughness Index). In this case, road profile data records are discreet and the step is big enough. According to the calculation method [11] the data, the information about the roughness height in one line is registered at every $0.147 \mathrm{~m}$. In dimensions the road profile registration is performed only at every $1 \mathrm{~m}$. The texture of the road surface is not registered with this profilograph. Data analysis confirms that it is possible to estimate essential differences of even and uneven asphalt concrete and gravel pavement roads profile with summarized data.

The waviness characteristic of all three types of the tracts was investigated in paper [9] and correlation functions of different road profile (Fig 1) prove this statement. Perpendicular or crossed and some banded to the axis, but not heigh, waves (Fig 2) are characteristic of the aforementioned waves.

According to the classical method [9] the data of the road tract profile were analysed. Dispersion of roughness $\sigma_{q}{ }^{2}$ and correlation function $R_{q}$ were calculated:

$$
\sigma_{q}^{2}=\lim _{L q \rightarrow \infty} \frac{1}{L q} \int_{0}^{L q} q_{0}^{2}(x) d x,
$$




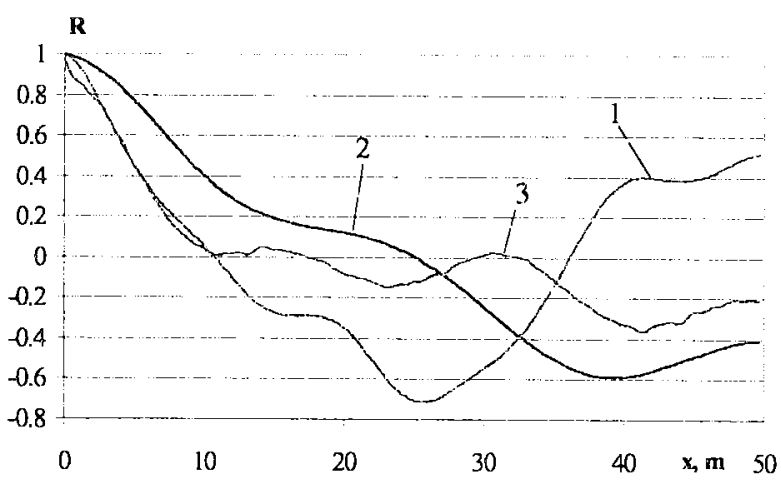

Fig 1. Correlation functions of summarized road tracks: 1 - even asphalt concrete; 2 - uneven asphalt concrete; 3 - gravel

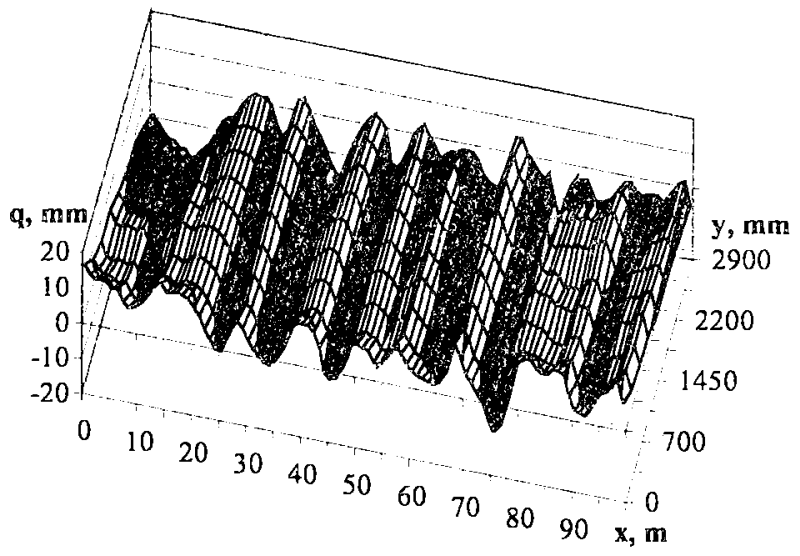

Fig 2. Dimensional fragment of the road profile

$$
R_{q}\left(x_{s}\right)=\frac{1}{L_{q} \sigma_{q}^{2}} \int_{0}^{L_{q}} q_{0}(x) q_{0}\left(x+x_{s}\right) d x,
$$

where, $L_{q}$ - length of analysed section, $q_{0}$ - height of roughness, estimated from the central line, $x_{s}-$ step.

Characteristic length of waves was specificated with harmonic analysis and the length of the waves setting the greater amplitude $R_{i}=\sqrt{{a_{i}^{2}+b_{i}^{2}}^{2}}$ :

$$
q(x)=\frac{x_{0}}{2}+\sum_{i=1}^{\infty} a_{i} \cos (i \omega x)+\sum_{i=1}^{\infty} b_{i} \cos (i \omega x)
$$

The analysis of the road profile is simplified because dimensional profile records (3D) are presented thicker by track by profilograph DYNATEST 5051 RPS. It makes possible more precise restoring of profile specific character in the contact zone of the tire. The data of road surface texture from [12] were used. Three types of surface textures (Table 1)-relative by even (I), middle (II) and very rough (III) were used. In Fig 3 the view of the dimensional surface textures is presented.
The statement that texture is a collection of accidental irregularities with the specific dominating form is possible. It was noticed that the surfaces with rough texture distinguish waviness with the shorter than profile waves (Fig 4).

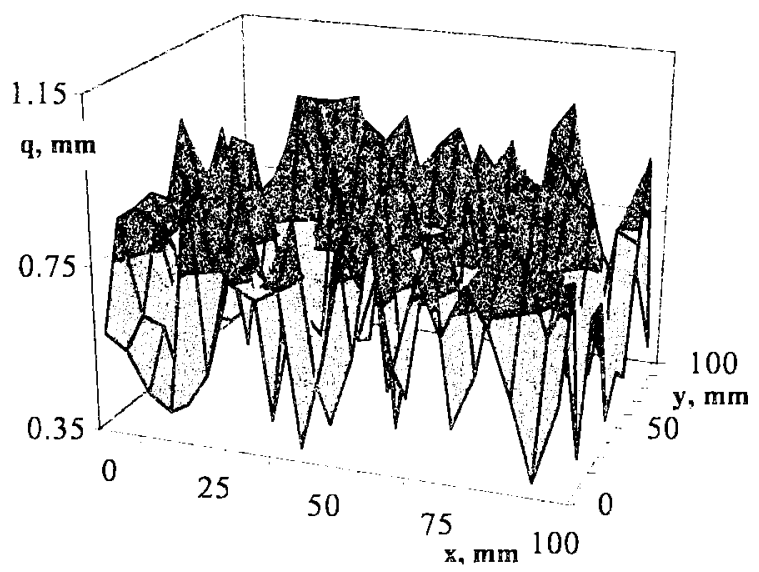

Fig 3. Dimensional fragment of the road surface texture

The data about the characteristics of the analyzed profiles and surface textures are presented in Table 1.

Determinative method of computation was used. Real road profile record was formed in one line for $2 \mathrm{D}$ type model of the tire and dimensional profile record for 3D type tire model. Surface texture of the road was estimated placing the data of surface texture on the road profile data.

The data of surface texture (control points are at every $2.5 \mathrm{~mm}$ ) are selected from the basic data file using generator of random numbers. In this way the calculated data of the road profile $q(x)$ or $q(x, y)$ were obtained.

We specify that the essential differences of the correlation function during the evaluation of the texture were not found (Fig 5).

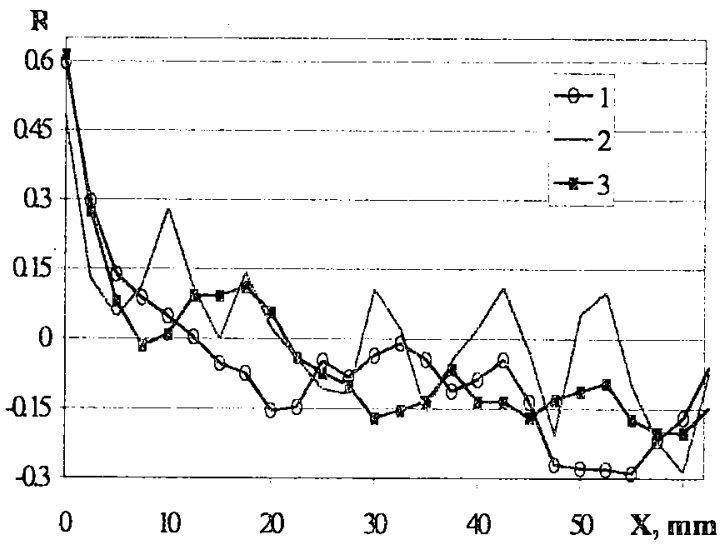

Fig 4. Correlation function of different surfaces texture (table 1) 1-I; 2-II; 3-III 
Table 1. Characteristics of the analyzed road surface profile and texture.

\begin{tabular}{|c|c|c|}
\hline Quality of road surface & $\begin{array}{c}\text { Dispersion } \\
\sigma_{\mathrm{q}}, \mathrm{mm}\end{array}$ & Characteristic wavelength, m \\
\hline Even asphalt concrete & 3,492 & $50-52$ \\
Uneven asphalt concrete & 12,437 & $75-77$ \\
Gravel & 13,667 & $45-47$ \\
\hline I (relative by even texture) & 0,276 & $0,04-0,10$ \\
II (middle texture) & 0,695 & - \\
III (very rough texture) & 1,667 & $0,06-0,14$ \\
\hline
\end{tabular}

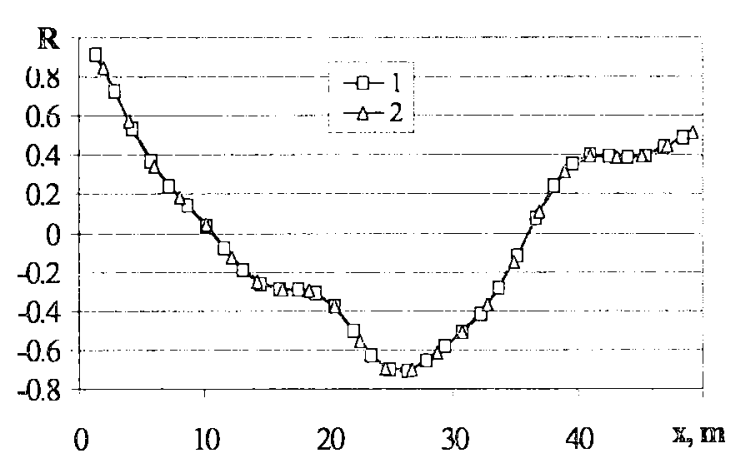

Fig 5. Correlation function of the profile evaluating the texture: 1 - with texiure; 2 - without texture

\section{Models of a Tire for the Description of the Smoothest Vehicle Movement}

Depending on the purpose of the model few models of the car tire are offered distinguishing linear $[1,2,3,13]$ or nonlinear $[6,4,14,15]$ characteristics.

For the more detailed investigation of the tire smoothing function we selected the model of the flexible narrow ring (2D) and a flexible band (3D). The first one (Fig 6, a) estimates the tire and road contact in a line and it is used when the record of profile is simplified, i.e. the road profile data in one line are known. The second one (Fig 6, b) estimates a dimensional contact between road and tire, but it demands on the full profile data where conditions of traffic band are reflected.

In both models the length of a tire contact was determinated according to the vertical deformation of the tire. Two extreme cases were analyzed: The tire does not get deformed in the radial direction and the contact length is equal to the arc length (this presumption is not precise because experimental data [2] confirm that then the tire in the contact zone is pressed). The second case is when the tire protector is crushed to chord length. The results confirm that computational method of the contact length does not have distinct influence on the results, if the rolling of the modern tires in good quality roads is analyzed.

Quarter car model (Fig 7) is used to determinate vertical deformation of the tire. Making presumption that stiffness characteristics of the tire and suspension are linear, the model can be described by the equation system:
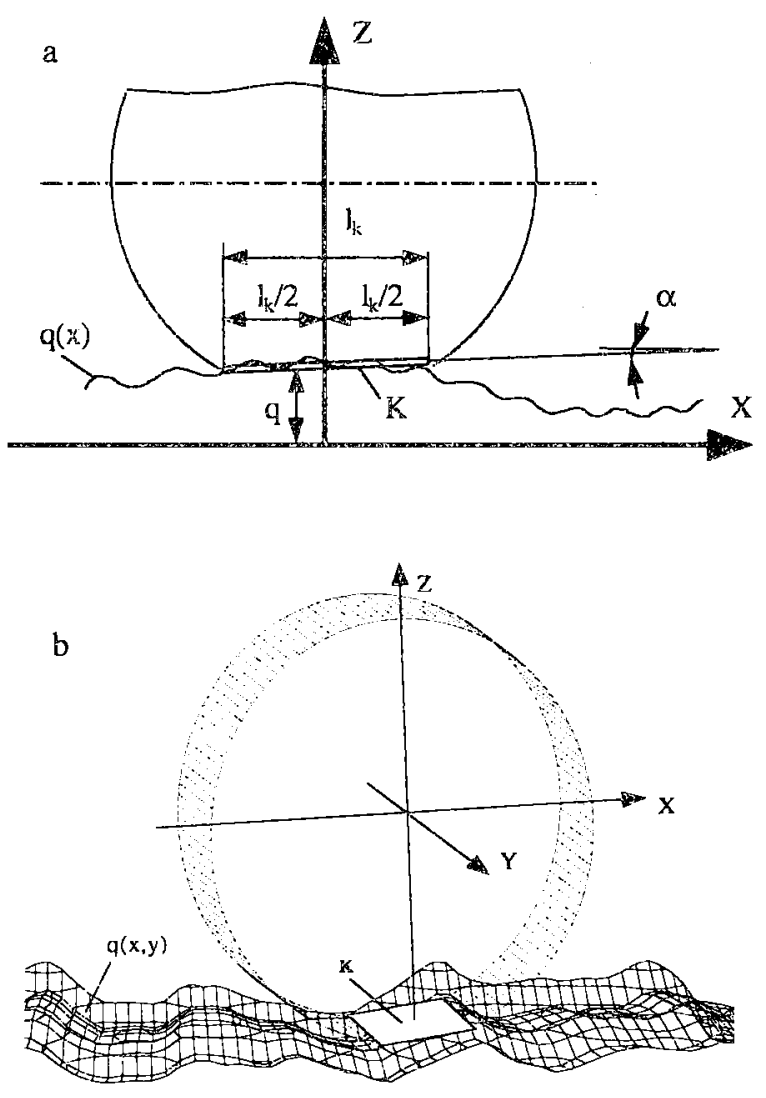

Fig 6. Models of tire: $a$ - flexible ring; $b$ - flexible band

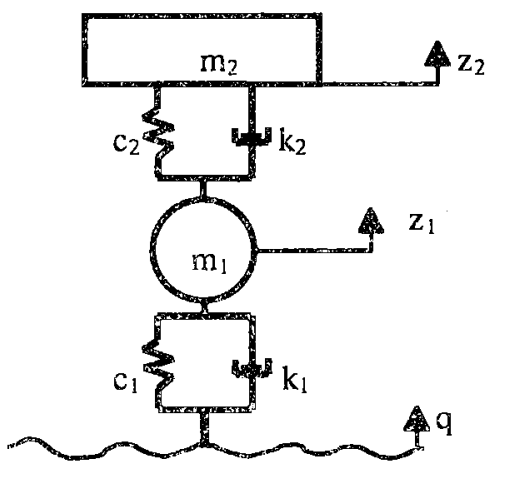

Fig 7. Quarter car model 


$$
\left\{\begin{array}{l}
\mathrm{m}_{2} \frac{d^{2} z_{2}}{d t^{2}}+k_{2}\left(\frac{d z_{2}}{d t}-\frac{d z_{1}}{d t}\right)+c_{2}\left(z_{2}-z_{1}\right)=0 \\
m_{2} \frac{d^{2} z_{2}}{d t^{2}}+m_{1} \frac{d^{2} z_{1}}{d t^{2}}+k_{1}\left(\frac{d z_{1}}{d t}-\frac{d q}{d t}\right)+c_{1}\left(z_{1}-q\right)=0
\end{array}\right.
$$

where $m_{2}$ - the sprung mass of car; $m_{1}$ - the unsprung mass of car; $a_{1}$-stiftuess of tire; $c_{2}$-stiffness of suspension elements; $k_{1}$ - tire damping; $q$-midale ordinate of the road surface profile under the car's wheel; $z_{1}$-vertical displacement of the unsprung mass; $z_{z}-$ vertical displacement of the sprung mass.

The system of equations is solved by the method of Runge - Kutta. In the initial calculations the model of a quarter car corresponds to VW Golf automobile, the driving speed is aqual to $100 \mathrm{~km} / \mathrm{h}$. Using this model the limits of changes of the tire contact length are established driving on the roads of different guality (Fig S). Moving on the asphalt concrets roads the contact length changes in the linits of $16 \%$. At about $15 \%$ of the way this length is ciose so the length under static load conditions. On the uneven gravel rood (Fig 8 ) the curve of the contact length is lowated in a more wide range. The cases were registered when the tire looses touch with the road and has the highest possible deformation. In this way the role of the tire rolling on very uneven roads is supposed to be more distinct.

The roads of various quaily and different models of the tires are presented in Fig 8 . They allow to affrm that it is possible to analyze the simplified tire model with the invariable contact length corresponding to the length of the static tire deformation when the car is moving on the asphalt concrete.

Investigating the role of a tire in the car and road interaction it is necessary to estimate that the domping coefficient $k_{1}$ (Fig 7) can be different for the different models of the tire construction. Different authors present different recommendations, in some investigations $[2,3]$, especially for the higher speeds, the recominended $k_{1}=0$.

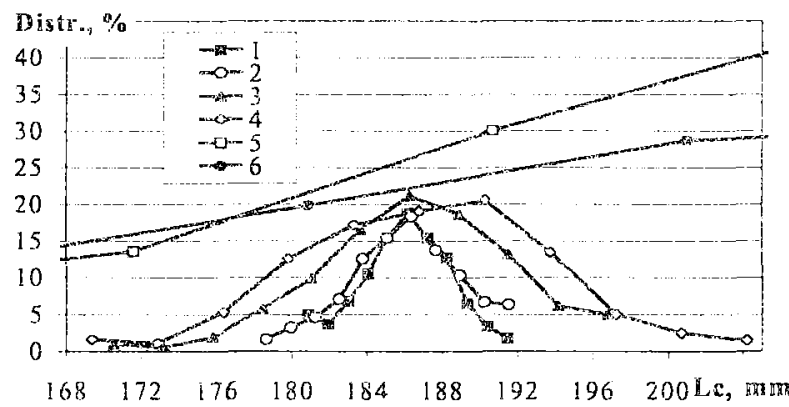

Fig 3. Distribution frequencies of the tire contact length on yarious quailty roads and for difierent models of tires:

1 - even asphalt concrete $2 \mathrm{D} ; 2$ - ever asphalt concrete 3D; 3 - uneven asphalt concrete $2 \mathrm{D}$;

4 - uneven asphalt concrete $3 \mathrm{D} ; 5$-gravel $2 \mathrm{D} ; 6$-gravel $3 \mathrm{D}$

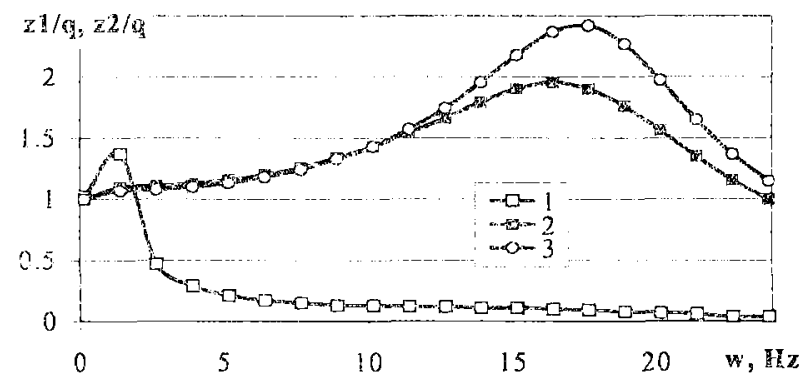

Fig 9. Frequentative characteristic of the car mass: 1 - sprung mass; $2-$ unsprung mass; 3 - unsprung mass, when tire camping $\mathrm{k}_{1}=0$

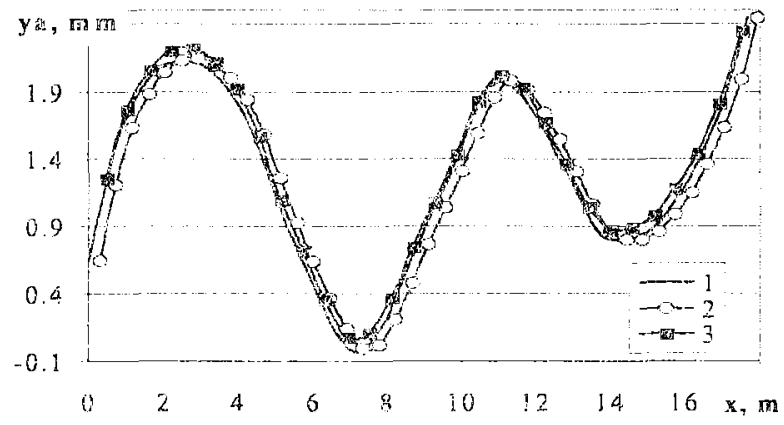

Fig 10. Influence of the tire model on body oscillations (fragment of the even asphalt concrete pavement with very rough tex(ure): 1 - contact point; 2 - 2D model; $3-3 \mathrm{D}$ model

The influence of the tire smoothing function on the frequentative characteristics of the quarter car model was analyzed. The results presented in Fig 9 are obtained analyzing the extreme damping coefficients presuming that the damping coefficient of the tire is equal to zero and the results investigate the modern tire $[1,4,5,14]$. A frequentative characteristic of the quaiter car model changes only for unsprung mass, in enough wide $14-22 \mathrm{~Hz}$ frequency tract where the dynamic coefficient of vertical deformation increases 1.2 times.

The results of the investigation of the quarter car model allow to aftixm that the model of the tire has no essential influence when the road with asphalt concrete pavement (Fig 10) is analyzed. Using different models of a tire the differences of amplitude of the body oscillations do not exceed $9 \%$ periods change $0.006 \mathrm{rad}$. In this case it is purposive to pay greater attention to unsprung mass oscillations.

\section{20 Tire Mode}

$2 \mathrm{D}$ model was used aiming to estimate the influence of the surface texture, the tire contact length and the approved tire model. The results (Table 2) show that $2 \mathrm{D}$ model is more sensitive to the surface textures than the dimensional model.

The dependence of the unsprung mass vertical displacement or the used type of the tire smoothing function 
Table 2. Dependence of dispersions $\sigma$ of the calculated profile roughness on the tire model and the surface texture

\begin{tabular}{|c|c|c|c|}
\hline \multirow{2}{*}{ Model } & \multicolumn{3}{|c|}{ Surface texture } \\
\cline { 2 - 4 } & I & II & III \\
\hline flat & 0,188 & 0,329 & 0,348 \\
\hline dimensional & 0,194 & 0,195 & 0,195 \\
\hline
\end{tabular}

is presented in Fig 11. It is possible to state that the estimation of change of the tire contact length which requires much complicated computation scheme is not very effective on the profile level and is not much different from the model with a point contact. The analysis of the flat tire model shows that the estimation of the surface texture can have the influence on the evaluation of the car movement on the profile level, i. e. on the level which has the influence on the operation of the car suspension. The results are not identical, if the same tract is modelled evaluating the texture influence and without it. The obtained results allow to simplify the smoothing function of the tire if roughness of the short waves does not have distinct influence on wheel and road interaction. Applying the model with the constant contact length we have established that the influence of the tire is more complicated. The irregularities of the surface texture level distinguish with very short waves $(0.04-0.14)$. These irregularities have the influence on the contact between tire and road.

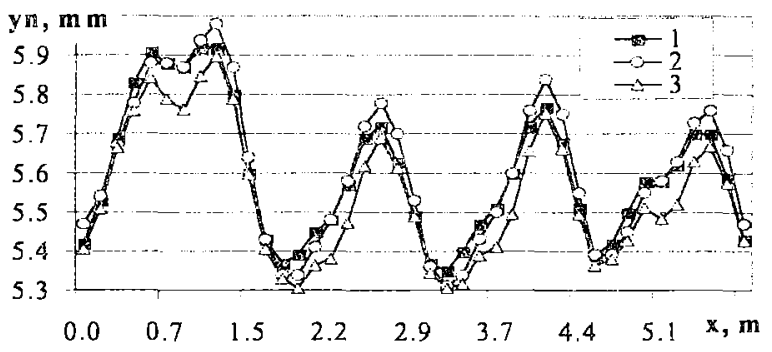

Fig 11. Displacement of car unsprung mass using different methods of estimation of contact length: 1 - contact line;

2 - contact changeable length line; 3 - contact point

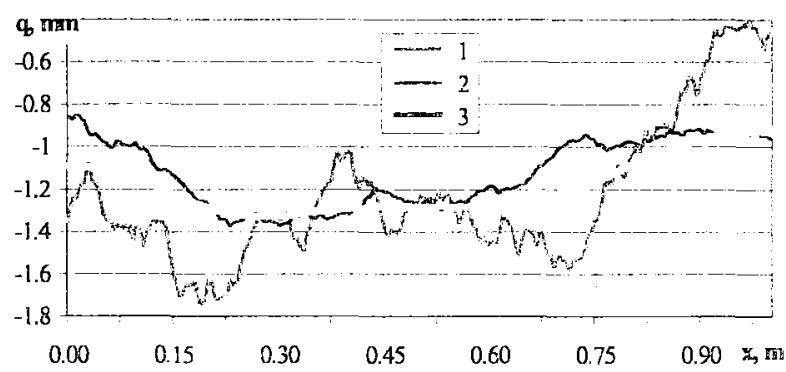

Fig 12. Trajectory of the tire center for the same profile with different surface texture: 1 - rough (III texture, Tablel); 2 - even (II texture, Table 1 ); 3 - without texture
Modelling the tires rolling on the same protile road with the different texture surface the influence of surface texture can be distinctly observed in middle coordinates of the tire (Fig 12). It means that the tire does not fully absorb the irregularities of the surface texture. Using the linear tire contact model (2D) we observed the waves of the surface texture amplitude level which lengths are located in the range of $0.25-0.7 \mathrm{~m}$, i. e. in the range of the profile level roughness. This problem is anaiysed in detail using 3D tire model.

\section{3 D Tire Model}

3D tire model is distinguished by a more smoothing function. In this case the surface texture has less influence. Even the determinative computation method of this model is more receptive for different criterions, but only in this way it is possible to estimate additional factors, such as: contact curvature, contact zone bending on the across and along plane.

In the dimensional surface texture data estimations it was observed that the irregularities are distributed accidentally and their forms are irregular. This statement is illustrated by the presented view of the dimensional surface terture fragment from the top (Fig 13). Here we can see accidentally located tops of the texture irregularities. For this reason the influence of the texture remains in the dimensional tire models for the even surfaces, it has the same size as in 2D model (Table 2) and for rough surfaces it is levelled.

The dependencies characterizing the movement of the car unsprung mass by modelling the operation of the tire applying different models were established (Fig 14). Dimensional model distinguishes the greatest smoothing function and rather precisely estimates the influence of the road irregularities. Analyzing the flat model of the tire we noticed that in this case (Fig 14 curve 2) the texture of road surface has a great influence. It involves the increase

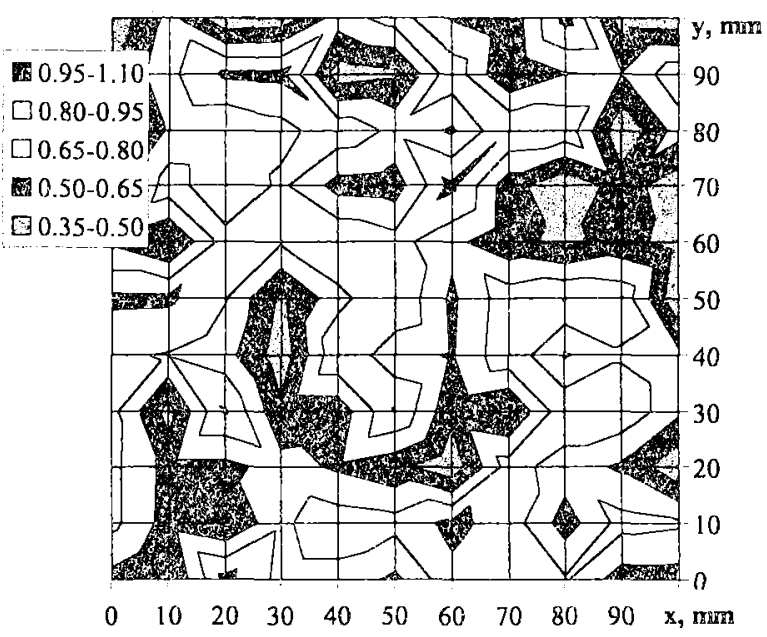

Fig 13. Fragment of the dimensional road surface texture 
of amplitude of road irregularities. The simplified dimensional model enough realistically reflects the irregularities of the road, but the differences of period and amplitude are observed, if compared with the influence of road irregularities.

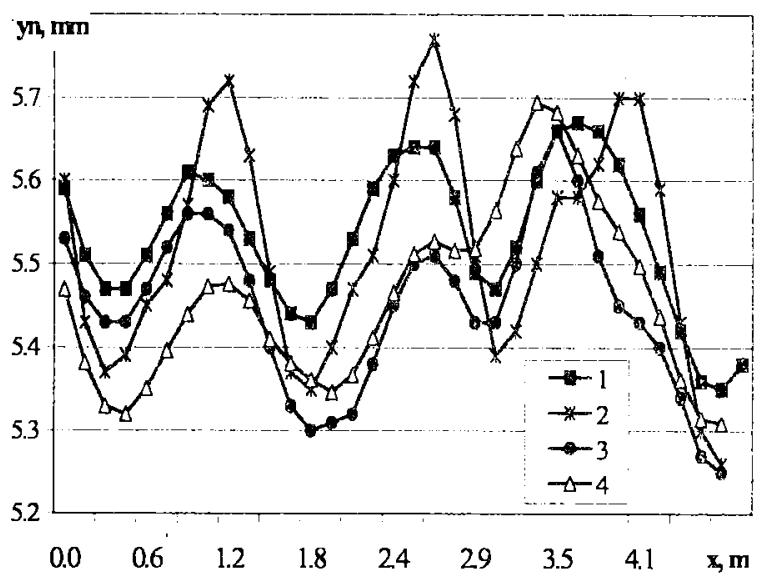

Fig 14. Movement of the car unsprung mass using different models to estimate the contact of tire and road: 1 - contact of tire and road - point; 2 - contact - line; 3 - simplified dimensional contact; 4 -dimensional model

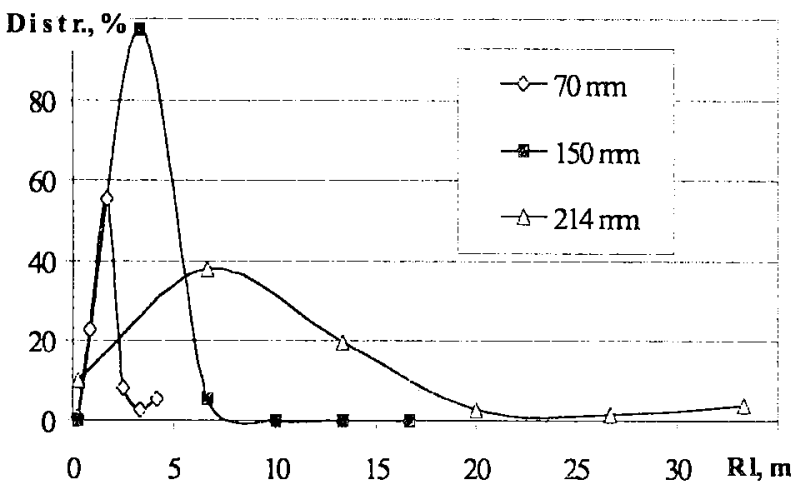

Fig 15. Distribution frequency of itregularities curvature radius in plane of wheel rolling for the different contact length of tire

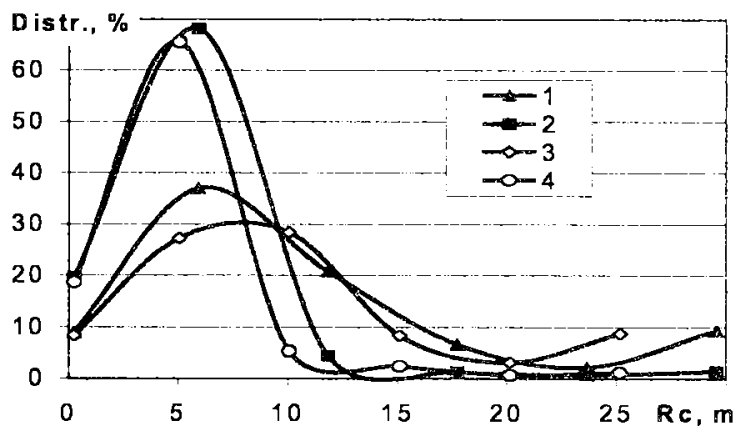

Fig 16. Distribution frequency of irregularities curvature radius in across plane of wheel rolling for the different contact width and for different models of tire: $1-150 \mathrm{~mm}$, model with constant contact length; $2-250 \mathrm{~mm}$, model with constant contact length; 3-150 mm, model with variable contact length; $4-250 \mathrm{~mm}$, model with variable contact length
The dimensional model of the tire gave the possibility to define more precisely some specific characteristics of the Lithuanians roads. Investigating the profile of the road in the level of tire contact dimensions, small enough curvature of irregularities in the longitudinal and across planes was observed (Fig 15, 16). Curvatures of irregularities with the radius equal to the tire diameter of about $20 \%$ of the road tract in different road tracts were observed.

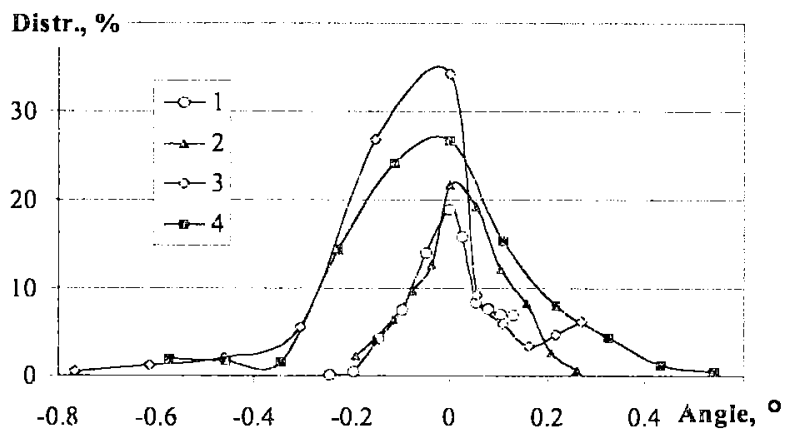

Fig 17. Distribution frequency of pavement pitch comers in tire contact zone: 1 - in along plane of wheel rolling for model with variable contact length; 2 - in along plane of wheel rolling for model with constant contact length; 3 - in across plane of wheel rolling for model with variable contact length; 4 - in across plane of wheel rolling for model with constant contact length

This must have influence on the stiffiness of the tire [2]. For more exact definition of the interaction model this feature must be estimated.

The angles of road pitch in the contact zone vary in limits of $0.3^{\circ}$ in longitudinal direction (Fig 17) and $0.8^{\circ}$ in across the direction of wheel rolling. Not big angles of inclination dominate. Comparing 3D model with constant contact length and more precise 3D model essential differences were not observed (Fig 16, 17). The obtained results allow to simplify significantly further modelling of tire and road interaction.

Performing the comparison investigation ten times increased volumes of calculations are evaluated, if a dimensional model with variable contact length is used. It allows to recommend to chose the description of smoothing function corresponding to solving task. In this case, evaluating the car smoothest movement for comparison calculations it is possible to use the model with the point contact of tire and road, if the profile records are made with profilograph DYNATEST 5051 RSP. By modelling uneven asphalt concrete, its dispersion of profile irregularities is $13.86 \mathrm{~mm}$; dispersion of unsprung mass movement equals to $14.05 \mathrm{~mm}$, if model with point contact is used and texture is not evaluated; with flat 2D model of tire, evaluating surface texture is $14.02 \mathrm{~mm}$; with dimensional 3D model, evaluating surface texture is $14.01 \mathrm{~mm}$. Standard square deviation between 2D and point models is $0.463 \mathrm{~mm}$; between $3 \mathrm{D}$ and point models it is $0.537 \mathrm{~mm}$; between $2 \mathrm{D}$ and $3 \mathrm{D}$ models it is $0.336 \mathrm{~mm}$. The deviations are formed because of the changes of local phases. 
Using the records of road profile the preparation of the data with the estimated smoothing function of a tire for the computations of the car smoothest movement is possible. For the further modeling of suspension motion the obtained data and the model with point contact of tire and road are used. If it is necessary, a radius of irregularity curvature in separate points can be presented. This preparation of data distinctly minimizes the volumes of the initial data files and further computations. There is no need to use 3D model if data of the wheel position or contact curvatures in the wheel rolling cross plane are not necessary. For the evaluation of the suspension operations the description of vertical displacement is necessary. For this description the tire model with a point contact an be used. The investigation of profile records allows to state that the method for IRI measurement offered by M. Sayers [11] is well considered selecting the criteria of the road profile measurements and the roughness estimation step. They describe the quality of the road precisely enough.

\section{Conclusions}

1. Using the model of a quarter car the models (with point contact, 2D and 3D) of a tire were investigated. The influence of tire smoothing function for the investigation of car and road interaction was estimated.

2. It was determinated that a tire does not fully smooth the irregularities of a surface texture level. In more precise models not only a road profile, but the texture of surface must be evaluated too.

3. Analyzing the records of road profile it was observed that about $20 \%$ radius of the irregularities curvatures at the tire and road contact zone can have the same size as the tire diameter. For this reason it is necessary to adjust the characteristics of tire stiffness.

4. It was determinated that the inclinations and bending angles of the contact zone are distributed in $0 \varnothing 0.6^{\circ}$ range and only $4 \%$ of them are distributed in narrow $\gg 1^{\circ}$ range.

5. For the comparison of computations investigating the smoothest movement it is possible to use the point model of wheel and road contact.

6. It is possible to state that the method for IRI measurement offered by M. Sayers [11] describes well the features of interaction between car and road when driving faster $(80-100 \mathrm{~km} / \mathrm{h})$.

\section{References}

1. Vong J. Theory of Ground Vehicles. Moscow: Maschinostroenie, 1989. $240 \mathrm{p}$ (in Russian).

2. Buchin B. L. Introduction to Pneumatic Tire Mechanic. Moscow: Chimia, 1988. 224 p (in Russian).

3. Levin M. A., Fufaev N. A. Rolling Theory of Deforming Wheel. Moscow: Nauka, 1989. 272 p (in Russian)

4. Bohm F. Dynamic Rolling Process of Tires as Layered Structures. Mechanics of composite materials. Vol 32, No 6, Riga: 1999, p 824-834.

5. Mitsche M. Theory of Vehicle. Dynamic of Vehicle. Tom 2 Vibrations. Warsaw: Publishing of Communications, 1987. $266 \mathrm{p}$ (in Polish).

6. Iwao K., Yamazaki I. A study on mechanism of tire - road noise. JSAE Rewiew; 17, 1996, p 139-144. ISSN 0389-4304.

7. Swayze J. L., Bachrach B. I., Shankar S. R. Suspension force optimization using qater - car model with elastomeric elemens. In: Proc. 1999 Noise and vibration conference, Vol 2. Michigan 1999, p 785 - 795. ISSN 1522-7537.

8. Kido I., Nakamura A., Hayashi T., Asai M. Suspension Vibration Analysis for Road Noise Using Finite Element Model. In: Proc. 1999 Noise and vibration conference, Vol 2. Michigan, 1999, p 1053-1060.

9. Dimaitis M., Sapragonas J. Description of Road Pavement in Car Suspension Modelling. Transport Engineering (Transportas), Vol XV, No 2. Vilnius: Technika, 2000, p 7276. ISSN 1392-1533 (in Lithuanian).

10. Dimaitis $M$. Investigation of Relationship Between Characteristics of the Car Suspension System and Road. Sumunary of doctor degree dissertation. Kaunas: Technology, 2000. $30 \mathrm{p}$ (in Lithuanian).

11. Sayers, St. M. Karamihas. Little book of profiling. University of Michigan Transportation Research Institute. Michigan, $1997.100 \mathrm{p}$.

12. Pakalnis A. Modelling of Car Wheel Performance. Kaunas: Technology, 2000. 30 p (in Lithuanian).

13. Liutkevicius M., Sapragonas J. Description of Tire by Flexible Ring Model. In: Proceedings of International conference „Mechanika - 2001“. Kaunas: Technology, 2001, p 70-75 (in Lithuanian).

14. Hassan S. N. Effect of tyre damping on the off-road vechicle stability and riding conditions. In: Proc. of conference, Technologii, Calitate, Masini, Materiale". Vol 4. Bucuresti: Tehnica, 1997, p 49-56.

15. Mau S. T., Tao X. Solution of circular sandwich ring under two forces acting along diameter. Joumal of engineering mechanics, Vol 126, No 4. Reston, VA: American society of civil engineers, 2000, p 348-357. ISSN 0733-9399. 